\title{
Research on the Application of Mobile Internet Information Products of New Agricultural Business Entities
}

\author{
Wei Tongyang ${ }^{1}$, Yang Yong*1 \\ Agriculture Information Institute, Chinese Academy of Agriculture sciences, Beijing, China
}

\begin{abstract}
Facing the current information age, this study aims to probe into the application of internet products of mobile terminals in the new agricultural business entities, and to analyze the advantages and disadvantages of the application. Based on this, the research group conducted an in-depth research on the new agricultural business entities in eight provinces and cities nationwide to understand the application of information products in the new agricultural business entities, in order to provide important reference and innovative ideas for the agricultural management departments and decision-making departments to carry out the work of training, fostering, guiding and serving new business entities.
\end{abstract}

\section{Foreword}

With the gradual penetration of new generation information technology to the field of agriculture, rural areas and farmers, the internet is becoming a new framework of agricultural organization, a new tool for farmers' production and management, a new carrier for the overall development of rural areas, and an important part for the implementation of Rural Revitalization Strategy. With the continuous improvement and upgrading of mobile communication infrastructure, the rapid popularization of smart phones and other terminal equipment, the comprehensive docking of internet in agricultural production, operation, management and service and the full integration and application of the whole industrial chain, the application programs of mobile internet terminals are emerging continuously with increasingly various types and more powerful functions, which, to a certain extent, optimized the promotion of agricultural technology, trading of agricultural products and the access to agricultural information.

At present, mobile phones are not only the means of life, but also the means of production to farmers. It enables more convenience for farmers to obtain market information and new technology and has become a good assistant in agricultural production. Compared to the long industrial chain, asymmetric information and other characteristics of traditional agriculture, the flat and transparent mode brought by internet shortens the distance between consumers and producers, reduces the credit risk and transaction cost between farmers and enterprises. The government also increasingly attaches importance to the important role of mobile phones in agricultural production. Since 2016, the Ministry of Agriculture and Rural Areas, together with local agricultural departments, has organized relevant units and enterprises to go to the countryside and carried out multi-layer, multi-type and multi-form mobile phone training courses, teach farmers to use mobile phones face to face, and focus on training professional households, family farms, cooperatives and other new agricultural operations, in order to improve people's ability to improve production, facilitate life, increase income and become prosperous by using mobile phones and realize improvement of the quality and efficiency of agricultural production through the mobile internet.

At present, about the research on the application of agricultural informatization of the new agricultural business entities, many scholars have discussed it from different angles. Liao Jinqiu constructed China's typical agricultural informatization construction mode from the two dimensions of regional agricultural economic development level and regional agricultural economic type, which broke the existing administrative division restrictions[1]. According to the comprehensive evaluation of Hunan agricultural resources, economic development level, science and technology level and other factors, Tan Yiping divided Hunan into four regions, and pointed out that measures should be taken in accordance with the local conditions and agricultural informatization should be conducted in different regions separately[2]. In the study on the informatization of a certain type of new agricultural business entities, Guo Yu's research on the informatization development and application mode of Guangxi family farm pointed out that the informatization used in production, operation management, circulation, promotion, social service and other links were less [3]. Yan Zhiye, through the research of informatization of 200 leading agricultural enterprises in Fujian Province and the analysis of the information demand and orientation, found that the development of information among enterprises was unbalanced and lack of scientific planning [4]. Han Xudong, based on the research of China's 3360 family

* Corresponding author wheatblue@163.com 
farms and large-scale planting and breeding households, mentioned that the insufficient ability of family farms and large-scale planting and breeding household had restricted the application of new technology to a large extent, and the small scale of production and operation and the backward construction of modern communication and logistics indicated that China's agricultural informatization and modernization still has a long way to go [5].

Based on the current information age wave, this study aims to probe into the application of internet products of mobile terminals in new agricultural business entities, and to understand its advantages and disadvantages. Based on this, the research group conducted an in-depth research on the new agricultural business entities in eight provinces and cities nationwide to understand the application of information products in the new agricultural business entities, in order to provide important reference and innovative ideas for the agricultural management departments and decision-making departments to carry out the work of training, fostering, guiding and serving new business entities, and also to provide the new-type entities with scientific ideas and methods in the information application in the future, in order to solve current agricultural sectors' problems of insufficient promotion, shortage of reserve force and shifted focus to management rather than service.

\section{Questionnaire Design and Research Site Selection}

\subsection{Research Framework}

First, the questionnaire is designed through the advanced research and expert consultation. After the field investigation and discussion centered around the topic, it is to take some counties and cities in Hebei, Inner Mongolia, Gansu, Shanxi, Chongqing and other provinces as research objects to launch the questionnaire survey, and conduct field discussion and investigation in some regions. Second, the launch of discussion and field research. The discussion and field research are centered around the application of mobile internet information products, the main content of the application, the identification of information in the application, the satisfaction of actual needs and practical applications, and the unadapt ability and problems in the application. Finally, the research report through the research and analysis. The collection, collation and statistical analysis of questionnaire and discussion data will lead to the research report and the analysis report on the demand and countermeasures of the mobile internet information service of new agricultural business entities.

\subsection{Questionnaire Design}

After interviewing organizations and consulting experts in the early stage, it is decided that the questionnaire of this survey consists of four parts.

The first part is about the basic information of the new agricultural operators, including age, gender, education, industrial scale, monthly telephone expenses, etc. The more detailed basic information of the respondents collected, the more detailed and comprehensive analysis the impact of different factors on information demand and mobile internet product application could be carried out.

The second part is about the information acquisition, including information acquisition awareness (whether there is a specific person responsible for information collection and release), information acquisition channels, whether there is a willingness to pay, etc., in order to understand the use and habits of the mobile internet products of the new agricultural business entities at this stage.

The third part is about the information demand, including the most needed agricultural information type, whether paid for the online agricultural information or not, payment doubts, etc., in order to understand the information demand of the new agricultural business entities at this stage and whether there are payment demand and payment doubts.

The fourth part is about the use frequency, satisfaction and improvement of the platform, including the use frequency, satisfaction and improvement suggestions of different types of agricultural information service platform from new agricultural business entities, and put forward the future direction of the platform from the perspective of user demand.

\subsection{Research Site Selection}

In 2018, eight provinces and cities including Guangxi, Yunnan, Inner Mongolia, Chongqing, Gansu, Hebei, Guizhou and Fujian were selected as the research sites for this survey. 100 questionnaires were distributed in each region in the form of field survey. The objects of this survey are new business entities including cooperatives, family farms, large-scale planting and breeding households, leading enterprises, agricultural material stores and agricultural technologic workers. In this survey, 805 questionnaires were sent out, and all were returned, reaching a $100 \%$ response rate. Random sampling was used to select samples. This paper mainly analyzes the application of mobile internet products of new agricultural business entities from information acquisition awareness, access channels, information payment, platform evaluation and other aspects.

\subsection{Survey of Basic Information}

According to the analysis of the individual characteristics of the new agricultural business entities, the proportion of agricultural technicians, cooperatives, family farms and large-scale planting and breeding households in the new agricultural business entities is more than $15 \%$. In the aspect of the person in charge, the education level of is mainly high school or technical secondary school, the age is mainly between 26 to 44 years old, with an average age of 42 , mostly of them are male, and the industrial scale is majorly within 1 million yuan. 


\section{Application of Internet Information Products of New Agricultural Business Entities}

\subsection{Access}

In the survey of user behavior, it is found that compared with the traditional way of obtaining information through newspapers and books, the proportion of obtaining the information through Wechat groups, mobile Apps and other online channels is significantly higher, up to $16-36 \%$, among which, the choice of Wechat groups accounts for the highest proportion to $57 \%$. This shows that it has become important ways to obtain agricultural information through mobile Apps, Wechat groups and Wechat Subscriptions based on mobile terminal.

Table1. Access to Agricultural Information

\begin{tabular}{lll}
\hline Channels & $\begin{array}{c}\text { Frequency } \\
\text { (person) }\end{array}$ & $\begin{array}{l}\text { Effective } \\
\text { percentage } \\
(\%)\end{array}$ \\
\hline Mobile Apps & 300 & 38 \\
Mobile networks & 342 & 43.3 \\
Wechat Subscriptions & 322 & 40.8 \\
Wechat groups & 456 & $\mathbf{5 7 . 7}$ \\
QQ groups & 232 & 29.4 \\
Mobile messages & 173 & 21.9 \\
Newspapers/books & 174 & 22 \\
TV and broadcasting & 264 & 33.4 \\
Person-to-person & 220 & 27.8 \\
\hline
\end{tabular}

\subsection{Application of Agricultural App Platform}

In the survey, it is found out that among the respondents, China's Agricultural Technology Promotion, Agricultural Online Bookstore and Agricultural Doctor accounted for a relatively high proportion. Among them, the Information Direct Reporting System of the New Agricultural Business Entities is an official management service platform specially built by the Ministry of Agriculture and Rural Areas to support and cultivate the new business entities, which provides the new business entities with allround and point-to-point access to credit, insurance, training, production, operation, product marketing and other services through direct connection of the entities, direct reporting of information, direct service and sharing, and the widely used sections are agricultural technology Q\&A and log sharing. Agricultural Online Bookstore is jointly developed by CNKI and a research institution, which is built based on CNKI's serial database and personalized knowledge service system. It is a platform for modern agricultural technology to conduct the personalized customized push service. The Agricultural Doctor is a free agricultural technology platform with a large number of users and frequent activity. Agricultural technology service is an important part in these three platforms, which is consistent with the result of the most urgent information needs and information acquisition of the new agricultural business entities analyzed earlier, which is, the information needs of new agricultural business entities at this stage are mainly related to agricultural production, and the agricultural technology information accounts for a large proportion in the searched agricultural information. Among other options chosen by new agricultural business entities, nearly one fifth of the respondents' use 12316 and Yimin Information Community, and about half of the respondents have not used Apps. The above analysis shows that as the two most important Apps of the Project of Information to the Households in the Rural Areas, Yinong Information Community and 12316 information service platform, from the perspective of the new agricultural business entities, although certain progress has been made in the current national informatization policies and measures, there is still some room for improvement.

Table2. Apps Been Used

\begin{tabular}{|c|c|c|}
\hline Agricultural Apps & $\begin{array}{c}\text { Frequency } \\
\text { (person) }\end{array}$ & $\begin{array}{l}\text { Effective } \\
\text { percentage }(\%)\end{array}$ \\
\hline $\begin{array}{l}\text { Agricultural } \\
\text { Doctor }\end{array}$ & 189 & 27.0 \\
\hline $\begin{array}{l}\text { Agricultural } \\
\text { Management }\end{array}$ & 118 & 16.8 \\
\hline $\begin{array}{l}\text { Cloud Planting and } \\
\text { Breeding }\end{array}$ & 80 & 11.4 \\
\hline $\begin{array}{l}\text { Agricultural } \\
\text { Technology }\end{array}$ & 151 & 21.5 \\
\hline Happy Farmers & 70 & 10.0 \\
\hline $\begin{array}{l}\text { China's Agricultural } \\
\text { Technology }\end{array}$ & 329 & 46.9 \\
\hline $\begin{array}{l}\text { Promotion, } \\
\text { Cloud Intelligent } \\
\text { Agriculture }\end{array}$ & 58 & 8.3 \\
\hline $\begin{array}{l}\text { Agricultural } \\
\text { Business }\end{array}$ & 41 & 5.8 \\
\hline $\begin{array}{l}\text { Learning } \\
\text { Agricultural Daily }\end{array}$ & 52 & 7.4 \\
\hline Blue Agriculture & 32 & 4.6 \\
\hline $\begin{array}{l}\text { Agricultural Online } \\
\text { Bookstore }\end{array}$ & 248 & 35.4 \\
\hline $\begin{array}{l}\text { New Agricultural } \\
\text { Direct Report }\end{array}$ & 47 & 6.7 \\
\hline Others & 65 & 9.3 \\
\hline
\end{tabular}

\subsection{Platform Utilizing Frequency}

Frequency of the utilization of each platform. It can be seen from the survey results that more than half of the new agricultural business entities only use mobile Apps and Wechat Subscriptions occasionally, and the entities using Wechat / QQ groups for an accumulated half an hour per day of is up to $19.4 \%, 0.5-1$ hour use accounting $18.4 \%$, 1-2 hour use accounting $10.5 \%$, and the proportion of using online websites for more than 2 hours per day is $12.1 \%$. It can be concluded though analysis that among the utilization frequency of the four platforms for the new agricultural business entities, mobile Apps rank the lowest, and Wechat / QQ groups and online websites enjoy higher utilization. This is in line with the results of the above analysis of information access, which indicates that there is further room for developing App users and it is necessary to continue to strengthen the publicity and promotion in the new agricultural business entities, and develop more users and their activeness in the platform. 
Table3. Frequency of Platform Utilization

\begin{tabular}{lcccc}
\hline \multirow{2}{*}{$\begin{array}{l}\text { Frequency } \\
\text { of }\end{array}$} & \multicolumn{4}{c}{ Effective percentage (\%) } \\
\cline { 2 - 5 } Utilization & $\begin{array}{c}\text { Wechat } \\
\text { /QQ } \\
\text { groups }\end{array}$ & $\begin{array}{c}\text { Mobile } \\
\text { Apps }\end{array}$ & $\begin{array}{c}\text { Wechat } \\
\text { Subscriptions }\end{array}$ & $\begin{array}{c}\text { Online } \\
\text { Websites }\end{array}$ \\
\hline Occasional & 42.8 & $\mathbf{6 2 . 3}$ & 50.9 & 49.8 \\
use & & & & \\
$0.5 \mathrm{~h} / \mathrm{d}$ & $\mathbf{1 9 . 4}$ & 14.3 & 18 & 15.3 \\
$0.5-1 \mathrm{~h} / \mathrm{d}$ & 15.6 & 12.7 & $\mathbf{1 8 . 4}$ & 14.5 \\
$1-2 \mathrm{~h} / \mathrm{d}$ & $\mathbf{1 0 . 5}$ & 6.7 & 6.2 & 8.4 \\
Over $2 \mathrm{~h} / \mathrm{d}$ & 11.7 & 4 & 6.5 & $\mathbf{1 2 . 1}$ \\
\hline
\end{tabular}

\subsection{Satisfaction Evaluation of the Platform}

In addition to the frequency of platform utilization, the satisfaction with the platform of the new agricultural business entities was also surveyed. More than half of the new agricultural business entities surveyed expressed their satisfaction with Wechat / QQ groups and online websites, and half of the respondents held a neutral attitude towards mobile apps. Therefore, the functions of the platform, which has room for improvement, still need to be improved, and the promotion and publicity of Apps should be strengthened to meet the demands of the majority of new agricultural business entities.

Table4. Satisfaction of the Platform

\begin{tabular}{lcccc}
\hline Satisfaction & $\begin{array}{c}\text { Wechat } \\
\text { /QQ } \\
\text { groups }\end{array}$ & $\begin{array}{c}\text { Mobile } \\
\text { Apps }\end{array}$ & $\begin{array}{c}\text { Wechat } \\
\text { Subscriptions }\end{array}$ & $\begin{array}{c}\text { Online } \\
\text { Websites }\end{array}$ \\
\hline Very & 4.4 & 5.8 & 4.7 & 2.6 \\
unsatisfied & & 2.3 & 2.3 & 1.8 \\
Unsatisfied & 3.3 & 51.3 & 47.1 & 43 \\
Neutral & 42.2 & 29.6 & 35.8 & 37.6 \\
Satisfied & 37.8 & 10.9 & 10.2 & 14.9 \\
Very & 12.4 & & & \\
satisfied & & & & \\
\hline
\end{tabular}

\section{Improvement Direction of the Platform}

After the survey of the utilization frequency and satisfaction of the platform, a further study from the perspective of the improvement direction of the mobile apps platform has been carried out. The survey results showed that more respondents hope that the platform can improve the content and information reliability. Among the respondents who chose other options, they hope onestop services such as information, policy, industrial development, capital, etc. could be launched, while some respondents hope video services to be provided. It shows that respondents hope to have only one-way services to be provided, but also the integrated and customized services. As mentioned above, what is needed in the field of agriculture is the provider or service provider of agricultural solutions, or the agricultural knowledge service based on a specific population.

\section{References}

1. Liao Jinqiu,An Sendong. Construction and Selection of regional agricultural informatization construction mode in China $[\mathrm{J}]$. Journal of Jiangxi University of Finance and Economics,2012, (03) (in Chinese).

2. Tan Yiping. An Analysis of the path of "Divisional Construction" of Rural agricultural informatization in Hunan Province $[\mathrm{J}]$. Journal of Economic Geography,2013, (01) (in Chinese)..

3. GUO Yu,Zeng Zhikang, et al. Research on current Situation and Application Mode of Family Farm informatization construction in Guangxi [ $\mathrm{J}]$. Agricultural Network information,2017, (09) (in Chinese).

4. Yan Zhiye. Informatization orientation and Demand Analysis of leading agricultural industrialization enterprises in Fujian Province $[\mathrm{J}]$. Chinese Agricultural Science Bulletin, 2011,(27) (in Chinese).

5. Han Xudong, Yang Huilian, et al. How does network sales affect the brand building of new agricultural business entities?- Based on an empirical study of 3,360 family farms and large breeding families nationwide $[\mathrm{J}]$. Journal of Agricultural and Forestry Economic Management,2018,(17) (in Chinese). 